\title{
Inactivated $E$. coli transformed with plasmids that produce dsRNA against infectious salmon anemia virus hemagglutinin show antiviral activity when added to infected ASK cells
}

OPEN ACCESS

Edited by:

Ricardo Flores,

Instituto de Biología Molecular y Celular de Plantas (UPV-CSIC), Spain

Reviewed by:

Beatriz Navarro Ramirez, Consiglio Nazionale delle Ricerche,

Francisco Tenllado, Consejo Superior de Investigaciones Cientificas, Spain

*Correspondence: Jaime Romero, Laboratorio de Biotecnología, Unidad de Alimentos, Instituto de Nutrición y

Tecnología de los Alimentos,

Universidad de Chile, Avenida El Libano 5524, Macul, Santiago, Chile jromero@inta.cl

Specialty section: This article was submitted to

Virology,

a section of the journal

Frontiers in Microbiology

Received: 02 December 2014 Accepted: 26 March 2015

Published: 16 April 2015

Citation:

García K, Ramírez-Araya S, Díaz Á, Reyes-Cerpa S, Espejo RT, Higuera G and Romero J (2015) Inactivated E. coli transformed with plasmids that produce dsRNA against infectious salmon anemia virus hemagg/utinin show antiviral activity when added to infected ASK cells.

Front. Microbiol. 6:300. doi: 10.3389/fmicb.2015.00300

\section{Katherine García ${ }^{1}$, Sebastián Ramírez-Araya ${ }^{1}$, Álvaro Díaz ${ }^{1}$, Sebastián Reyes-Cerpa ${ }^{2}$, Romilio T. Espejo ${ }^{1,3}$, Gastón Higuera ${ }^{1}$ and Jaime Romero ${ }^{1 *}$}

1 Laboratorio de Biotecnología, Unidad de Alimentos, Instituto de Nutrición y Tecnología de los Alimentos, Universidad de Chile, Santiago, Chile, ${ }^{2}$ Facultad de Química y Biología, Centro de Biotecnología Acuícola, Universidad de Santiago de Chile, Santiago, Chile, ${ }^{3}$ Centro Nacional de Genómica y Bioinformática (Omics Solutions), Santiago, Chile

Infectious salmon anemia virus (ISAV) has caused great losses to the Chilean salmon industry, and the success of prevention and treatment strategies is uncertain. The use of RNA interference (RNAi) is a promising approach because during the replication cycle, the ISAV genome must be transcribed to mRNA in the cytoplasm. We explored the capacity of $E$. coli transformed with plasmids that produce double-stranded RNA (dsRNA) to induce antiviral activity when added to infected ASK cells. We transformed the non-pathogenic Escherichia coli HT115 (DE3) with plasmids that expressed highly conserved regions of the ISAV genes encoding the nucleoprotein (NP), fusion (F), hemagglutinin $(\mathrm{HE})$, and matrix $(\mathrm{M})$ proteins as dsRNA, which is the precursor of the RNAi mechanism. The inactivated transformed bacteria carrying dsRNA were tested for their capacity to silence the target ISAV genes, and the dsRNA that were able to inhibit gene expression were subsequently tested for their ability to attenuate the cytopathic effect (CPE) and reduce the viral load. Of the four target genes tested, inactivated $E$. coli transformed with plasmids producing dsRNA targeting HE showed antiviral activity when added to infected ASK cells.

Keywords: double-stranded RNA, infectious salmon anemia virus, bacterial delivery, antiviral, aquaculture

\section{Introduction}

In recent years, the Chilean salmon farming industry has grown into one of the major salmon producers worldwide. However, the appearance of the infectious salmon anemia virus (ISAV) has strongly affected the salmon industry, resulting in high mortality and substantial economic losses (García et al., 2013). ISAV belongs to the genera Isavirus from the Orthomyxoviridae family (Krossøy et al., 1999; Palese and Shaw, 2007). It possesses a segmented genome of single-stranded RNA with negative polarity (Kulshreshtha et al., 2010) that encodes eight structural proteins and two non-structural proteins (Cottet et al., 2011). Infection with ISAV principally affects Atlantic salmon and other salmonid species (Raynard et al., 2001), causing systemic disease. The clinical 
and pathological signs of the disease can result in death (Evensen et al., 1991), causing a strong decline in production with serious economic costs. These losses are due to the limited availability of effective vaccines and specific antiviral treatments (García et al., 2013). To date, no effective pharmacological treatment has been developed for this disease, and the success of prevention strategies against ISAV is uncertain.

Considering the limitations of existing treatments, a plausible solution is the use of RNA interference (RNAi), which is a very promising alternative against viral diseases (Peng et al., 2005; Sarathi et al., 2008b; DeVincenzo et al., 2010). RNAi is an intracellular process by which small interfering RNAs (siRNAs) direct the degradation of matching messenger RNA (mRNA) (Hammond et al., 2000; Provost et al., 2002; Hannon and Conklin, 2004; Tijsterman and Plasterk, 2004; Gregory et al., 2005), preventing its translation into protein and causing gene silencing (Hammond, 2005). Effective delivery to the appropriate cells remains a major obstacle to successful RNAi. Several strategies exist, from the delivery of naked siRNA duplexes to more complex methods, including the systemic delivery of siRNA complexes as conjugates (La Fauce and Owens, 2012) and the use of non-pathogenic bacteria for delivery of dsRNA (Sarathi et al., 2008a). Each approach has its advantages and disadvantages, which must be considered when choosing a delivery strategy. Recently, the development of RNAi therapies for viral disease treatment has been suggested for aquatic organisms (Lima et al., 2013). Successful reports have been published on studies using RNAi technology against white spot syndrome virus (WSSV) (Sarathi et al., 2008a,b), CyHV-3 virus (Gotesman et al., 2014) and the virus that causes hemorrhagic septicemia, VHSV (Ruiz et al., 2009; Kim and Kim, 2011; Kim et al., 2012). VHSV, like ISAV, has a single-stranded RNA genome of negative polarity (Kulshreshtha et al., 2010), which makes this strategy very encouraging for our purposes.

In this work, we hypothesized that blocking the expression of four structural viral genes, nucleoprotein (NP), which is bound in multiple subunits to the genomic RNA (Palese and Shaw, 2007), matrix protein $(\mathrm{M})$, which constitutes the most abundant structural protein (Falk et al., 2004; Palese and Shaw, 2007), hemagglutinin (HE) (Falk et al., 2004; Müller et al., 2010) and fusion (F) (Falk et al., 2004; Palese and Shaw, 2007), which are the surface glycoprotein, would circumvent ISAV replication. To this end, we explored the use of bacterially synthetized dsRNAs directed against NP, F, HE, and $\mathrm{M}$ to prevent the synthesis of these proteins by specific degradation of their respective mRNAs and decrease the viral load and attenuation of CPE in ASK cells.

\section{Materials and Methods}

\section{Cell Culture and Virus}

Atlantic salmon kidney cells (ASK) were acquired from the ATCC (ATCC ${ }^{\circledR}$ CRL-2747) (Devold et al., 2000). Monolayers of ASK were maintained at $15^{\circ} \mathrm{C}$ in Leibovitz medium (L-15, Gibco) supplemented with 10\% fetal bovine serum (FBS, Gibco), penicillin (100 U/ml, Gibco), streptomycin (100 $\mathrm{g} / \mathrm{ml}$, Gibco), gentamycin $(50 \mu \mathrm{g} / \mathrm{ml}$, US Biological) and $\beta$-mercaptoethanol (55 mM, Bio-Rad, USA). A viral inoculum stock of ISAV genotype HPR35, with a titer of TCID50 $=10^{7} / \mathrm{mL}$, was kindly provided by $\mathrm{ADL}$ diagnostics. The virus was propagated in monolayers of $70 \%$ confluent ASK cells as described in the viral infection section. All supernatants of the culture (aliquots of virus) were stored at $-80^{\circ} \mathrm{C}$.

\section{Viral Infection}

ASK cells were grown in 6-well plates to $70 \%$ confluence. At this point, the cells were infected with a $1 / 10$ dilution of viral stock $\left(\mathrm{TCID}_{50}=10^{7}\right)$ prepared in non-supplemented L-15 medium. The virus was allowed to adsorb for $4 \mathrm{~h}$. Then, the monolayer was washed twice with phosphate-buffered saline (PBS), and supplemented L-15 was added. The cells were incubated at $15^{\circ} \mathrm{C}$ for 11 days post-infection (dpi) until the cytopathic effect (CPE) was observed (Dannevig et al., 1995). At the end of infection, supernatants of the culture were harvested and stored at $-20^{\circ} \mathrm{C}$ for further analysis. The $\mathrm{CPE}$ observed during infection was followed using an inverted Motic model EA31 microscope. Five visual fields per well were recorded using a Motic cam 2500 and Motic Image Plus 2.0 software.

\section{Identification of Conserved Sequences in ISAV Genes}

Reference genomic sequences of the ISAV NP (NC_006502.1), F (NC_006500.1), HE NC_006499.1), and M (NC_006497.1) genes were identified in NCBI databases (http://www.ncbi.nlm.nih.gov/ genome). Each sequence was compared with the sequences in GenBank using blastn (Altschul et al., 1990); the e-value parameter was adjusted to $1.10 \mathrm{e}^{-5}$, and the search was restricted to sequences of the ISA virus taxa (txid: 55987) and Chilean isolates (Table 1). The remaining parameters used were the default values. Groups of identified sequences were aligned using ClustalX (Larkin et al., 2007), decreasing the penalties for the occurrence of spaces and using the default input parameters. All alignments were adjusted manually. Incomplete sequences or conflicts in sequencing were eliminated from the analysis. From the alignment, a consensus sequence of $500 \mathrm{bp}$ was searched for each viral genomic sequence and selected for dsRNA design. Each of these sequences was compared with the Salmo salar database (Di Génova et al., 2011) to evaluate the off-target effects of the RNAi.

\section{Construction of dsRNA-Producing Vectors Targeting NP, F, HE, and M}

Total viral RNA was extracted from $200 \mu \mathrm{L}$ of supernatants of ISAV-infected ASK cells using the Total RNA Kit I (Omega Biotek) according to the manufacturer's instructions. cDNA was synthetized as follows: $4 \mu \mathrm{L}$ RNA plus $1 \mu \mathrm{L}$ of random primer $\left(0.5 \mathrm{mg} / \mathrm{mL}\right.$; Promega, USA) were heated for $5 \mathrm{~min}$ at $70^{\circ} \mathrm{C}$. Immediately after this step, $15 \mu \mathrm{L}$ of reverse transcription mix was added (dNTPs, $\mathrm{MgCl}_{2}$, RNasin, $5 \mathrm{X}$ buffer, Improm-II RT; Promega, USA), and the samples were incubated at $25^{\circ} \mathrm{C}$ for $5 \mathrm{~min}, 42^{\circ} \mathrm{C}$ for $60 \mathrm{~min}$ and $70^{\circ} \mathrm{C}$ for $15 \mathrm{~min}$. To amplify the $500 \mathrm{bp}$ conserved region that was previously selected, 3NP, 5F, $6 \mathrm{HE}$, and $8 \mathrm{M}$ primers (Table 2), containing recognition sites for the SacII or XhoI restriction enzymes, were used independently for PCR amplification. The following thermal profile was used: 1 cycle of $5 \mathrm{~min}$ at $95^{\circ} \mathrm{C}, 30$ cycles of $30 \mathrm{~s}$ at $95^{\circ} \mathrm{C}, 30 \mathrm{~s}$ at $55^{\circ} \mathrm{C}$, and 
TABLE 1 | GeneBank accession of Chilean ISAV isolates sequences genes used for the alignments in this study.

\begin{tabular}{ll}
\hline Viral segment & GenBank accession \\
\hline Nucleoprotein & DQ520594.1; GU830905.1; GU830897.1 \\
\hline Fusion protein & FJ592146.1; FJ592163.1; EU449765.1; GU830899.1; \\
& FJ592162.1; FJ592165.1; EU130923.1; EU849005.1; \\
& EU849011.1; FJ592140.1; FJ592143.1; EU449768.1; \\
& EU849007.1; EU449767.1; EU552491.1; FJ592142.1; \\
& FJ592150.1; EU849006.1 \\
\hline \multirow{2}{*}{ Hemagglutinin protein } & EU849018.1; GU830900.1; FJ594303.1; FJ594301.1; \\
& FJ594326.1; FJ594317.1; EU851043.1; EU271682.1; \\
& EU849012.1; EU849015.1; EU625681.1; EU625675.1; \\
& FJ594325.1; EU849017.1; EU625677.1; FJ594319.1; \\
& EU625668.1; FJ594296.1; EU625678.1; EU625674.1; \\
& FJ594323.1; EU625671.1; EU849016.1; JQ712975.1; \\
& EU849013.1; EU849014.1; FJ594297.1; EU625676.1; \\
& EU625669.1; EU625670.1; FJ594285.1; FJ594328.1; \\
& EU625667.1; FJ594292.1; FJ594332.1; EU625679.1; \\
& FJ594306.1; FJ594315.1; GU830908.1; EU65672.1; \\
& FJ594316.1; FJ594295.1; EU625666.1; FJ594294.1; \\
& EU625680.1; FJ594284.1; FJ477897.1
\end{tabular}

Matrix protein

AF312315.1; GU830902.1; GU830910.1

$30 \mathrm{~s}$ at $72^{\circ} \mathrm{C}$ and a final extension of $10 \mathrm{~s}$ at $72^{\circ} \mathrm{C}$. Subsequently, each PCR product was cloned into pGEMT easy (Promega, USA), cut simultaneously with the SacII (New England Biolabs, USA) and XhoI (New England Biolabs, USA) restriction enzymes and ligated into the L4440 vector (graciously donated by Cold Spring Harbor Laboratory, NY, USA), which contains T7 promoter sites flanking each side of the multiple cloning site (MCS). L4440 plasmids carrying NP, F, HE, or M fragments were sequenced in Macrogen (USA) to confirm the sequence and subsequently electroporated into Escherichia coli bacterial strain HT115 (DE3), an RNase III-deficient non-pathogenic strain (graciously donated by Cold Spring Harbor Laboratory, NY, USA).

\section{Production and Quantitation of Antiviral dsRNA}

E. coli HT115 (DE3) carrying L4440 vectors with NP, F, HE or $\mathrm{M}$ inserts were grown in $10 \mathrm{~mL}$ of $\mathrm{LB}$ medium supplemented with $100 \mu \mathrm{g} / \mathrm{mL}$ ampicillin (Winkler, Chile). Induction of double-stranded RNA (dsRNA) was performed with $2 \mathrm{mM}$ IPTG (Invitrogen, USA) for $4 \mathrm{~h}$, and a total nucleic acid extraction was performed. The bacterial pellet was resuspended in $5 \mathrm{~mL}$ of $70 \%$ ethanol in PBS, incubated at room temperature for $5 \mathrm{~min}$ and collected by centrifugation at $6000 \mathrm{~g}$ for $5 \mathrm{~min}$ at $4^{\circ} \mathrm{C}$. Then, the bacterial pellet was resuspended in $1 \mathrm{~mL}$ of $150 \mathrm{mM}$ $\mathrm{NaCl}$ (Winkler, Chile) and incubated at room temperature for 1 $\mathrm{h}$; the centrifugation was then repeated for $10 \mathrm{~min}$. The supernatant was collected, and the genetic material was allowed to precipitate at $-20^{\circ} \mathrm{C}$ overnight. Afterwards, the supernatant was centrifuged for $30 \mathrm{~min}$ at $13000 \mathrm{~g}$ at $4^{\circ} \mathrm{C}$, and the formation of a white pellet was observed (Posiri et al., 2013). These nucleic acids were treated with $1 \mu \mathrm{L}$ RQ1-RNase free DNase (Promega, USA) and $8 \mathrm{M}$ lithium chloride (Winkler, Chile) to precipitate and remove any single-stranded RNA. Finally, the samples were treated with $8 \mathrm{M}$ lithium chloride to precipitate the dsRNA. To finish, dsRNA was resuspended in $170 \mu \mathrm{L}$ nuclease-free water (Winkler, Chile). The purified dsRNA was quantified using the DNA 1000 LabChip ${ }^{\circledR}$ kit on a Bioanalyzer Agilent 2100 (Agilent Technologies, USA). To verify the identity of cloned dsRNA, purification of each dsRNA from a $1 \% \mathrm{w} / \mathrm{v}$ agarose gel was performed. Each dsRNA $(1 \mu \mathrm{L})$ was used to synthesize cDNA as described above. Subsequently, conventional PCR was performed using primers $\mathrm{NPi}, \mathrm{Fi}, \mathrm{HEi}$, and Mi to amplify an internal section of the conserved regions of ISAV. The thermal profile used was 1 cycle of $5 \mathrm{~min}$ at $95^{\circ} \mathrm{C}, 30$ cycles of $30 \mathrm{~s}$ at $95^{\circ} \mathrm{C}, 30 \mathrm{~s}$ at $55^{\circ} \mathrm{C}$, and $30 \mathrm{~s}$ at $72^{\circ} \mathrm{C}$ and a final extension of $10 \mathrm{~s}$ at $72^{\circ} \mathrm{C}$.

\section{Bacterial Co-Localization Assay}

ASK cells were seeded into a 24 well-plate at a density of $1 \times 10^{5}$ cells/well. After 2 days, the cells were incubated for $40 \mathrm{~min}$ with the fluorescent probe CellTracker ${ }^{\mathrm{TM}}$ Orange CMRA (Invitrogen, USA) at a final concentration of $10 \mu \mathrm{M}$. Then, the cells were washed three times with PBS and treated with attenuated $E$. coli HT115 (carrying the green pBADT plasmid) overexpressing green fluorescent protein (GFP) in supplemented L-15 media at a multiplicity of infection (MOI) of 500 bacteria/cell (the maximum MOI that did not cause cell damage). Attenuation of the bacterial culture was performed by adding formaldehyde at a final concentration of $0.5 \% \mathrm{v} / \mathrm{v}$ and incubating for $20 \mathrm{~min}$ at room temperature. Immediately after this step, the bacterial culture was centrifuged and washed twice with PBS, quantified in a PetroffHausser chamber and used for analysis. The incubation of ASK cells with attenuated bacteria in supplemented L-15 media was followed by 4 days at $15^{\circ} \mathrm{C}$. During the assay, slides with cell samples were removed at $0,24,48$, and $96 \mathrm{~h}$. Each slide was fixed with $4 \%$ paraformaldehyde (PFA) for $10 \mathrm{~min}$ and then treated with $50 \mathrm{mM} \mathrm{NH}_{4} \mathrm{Cl}$ for $10 \mathrm{~min}$. Finally, the slides were mounted in 1,4-diazabicyclo[2.2.2] octane (DABCO) and visualized using a Nikon $\mathrm{C}^{+}$confocal microscope. Phase contrast photographs were taken using a Carl Zeiss LSM 510 confocal microscope with a DIC 3.4 filter.

\section{Antiviral Treatment in ISAV-Infected ASK Cells}

ASK cells were grown in 6-well plates to $70 \%$ confluence. Then, the cells were infected with ISAV HPR35 and treated individually with attenuated E. coli HT115 carrying dsRNA against HE, NP, $\mathrm{M}$, or $\mathrm{F}$ individually or in a mixture of equal proportions. Additionally, a treatment with attenuated E. coli carrying an empty pL4440 vector was included. In all cases, we used a MOI of 500 (bacteria/cell) because it was the maximum MOI that did not cause cell damage. The attenuation process was the same as described above (in the bacteria co-localization assay). Cells that underwent different treatments were harvested at $11 \mathrm{dpi}$ and incubated in EDTA-free protease inhibitor buffer (Roche, USA). These samples were used for real-time PCR and western blot analyses. In parallel, the supernatants were collected and used to determine the viral titer using a viral plaque assay. The CPE observed during each treatment was followed in an inverted Motic model EA31 microscope and recorded photographically 
TABLE 2 | List of the primers used in this study.

\begin{tabular}{|c|c|c|c|c|c|}
\hline Primer & Experimental protocol & Primer orientation & Sequence & Product length (bp) & References \\
\hline \multirow[t]{2}{*}{$3 \mathrm{NP}$} & Cloning & Sense & CCGCGGAGCTITCTGATTGACCCACCT & 480 & This work \\
\hline & & Antisense & CTCGAGAAGCATCTCCCTGATAGCGC & & Cottet et al., 2010 \\
\hline \multirow[t]{2}{*}{$5 \mathrm{~F}$} & Cloning & Sense & CCGCGGCCAAATGCGGGAGGAAAGGA & 450 & This work \\
\hline & & Antisense & CTCGAGCTCCTGGGAATGCTCTCTGG & & This work \\
\hline $6 \mathrm{HE}$ & Cloning & Sense & CCGCGGCTGCAGGCCAAAAACGGAAA & 492 & This work \\
\hline $8 \mathrm{M}$ & & Antisense & CTCGAGCCCAGGAGCACCATCTTCTC & & This work \\
\hline \multirow[t]{2}{*}{$3 \mathrm{NPi}$} & PCR & Sense & CAATGGTTGCAACAGCATTC & 205 & This work \\
\hline & & Antisense & ACTTGCCAGCTTCGATCTGT & & This work \\
\hline \multirow[t]{2}{*}{$5 \mathrm{Fi}$} & PCR & Sense & ATCTGCGGAGGTACAACAGG & 224 & This work \\
\hline & & Antisense & ACCAGTACAGGCGATGGAAC & & This work \\
\hline $8 \mathrm{Mi}$ & & Antisense & TCTGCATCCTGCTGTGTAGC & & This work \\
\hline \multirow[t]{2}{*}{$3 \mathrm{NPq}$} & qPCR & Sense & ATGGCCGATAAAGGTATG & 348 & This work \\
\hline & & Antisense & TTGTTGTCAACCATGCCAC & & This work \\
\hline \multirow[t]{2}{*}{$5 \mathrm{Fq}$} & qPCR & Sense & CTGTTGCACTCAGCATGGAT & 257 & This work \\
\hline & & Antisense & CTCCTGGGAATGCTCTCTGG & & This work \\
\hline \multirow[t]{2}{*}{$6 \mathrm{HEq}$} & qPCR & Sense & GGCACGATTCATAATTTTATTCC & 223 & This work \\
\hline & & Antisense & TGAAGCAGATGAGTGGAAGG & & This work \\
\hline \multirow[t]{2}{*}{$8 \mathrm{Mq}$} & qPCR & Sense & TGGATACAAAAACATCTACCATGC & 200 & This work \\
\hline & & Antisense & TGGTTCAAGGTTTTACTTCAC & & This work \\
\hline \multirow[t]{2}{*}{ Mx } & qPCR & Sense & CTGGAGGAACCAGCAGTCAA & 273 & Abid et al., 2013 \\
\hline & & Antisense & TAAGGGTCGGTCGTCTTCCT & & \\
\hline
\end{tabular}

using a Motic cam 2500; five visual fields were randomly analyzed with Motic Image Plus 2.0 software.

\section{Real-Time qPCR Analysis}

The procedure for total RNA extraction and cDNA synthesis was the same as described above except we used primer pairs $\mathrm{NPq}, \mathrm{Fq}, \mathrm{HEq}$, and Mq (Table 2) instead of random primers. To estimate the mRNA expression levels of NP, F, HE, and M, real time RT-PCR was carried out using the Corbett Rotor-Gene 6000 Thermal Cycler (Corbett Life Science) according to the manufacturer's instructions and using Rotor-Gene Version 1.7.87 software. All reactions were performed in triplicate. The PCR primer pairs $\mathrm{NPq}, \mathrm{Fq}, \mathrm{HEq}, \mathrm{Mq}$ and the control gene $\beta$-actin (Olsvik et al., 2005) are shown in Table 2. The PCR reactions were performed in a final volume of $10 \mu \mathrm{L}$ using Light Cycler ${ }^{\circledR} 480$ SYBR Green I Master Mix (Roche, USA) with $1 \mu \mathrm{L}$ of cDNA and $1 \mu \mathrm{L}$ of each $50 \mathrm{mM}$ primer. The thermal profile of real-time qPCR was as follows: hold for 1 cycle of $5 \mathrm{~min}$ at $95^{\circ} \mathrm{C}$ followed by 40 cycles of $15 \mathrm{~s}$ at $95^{\circ} \mathrm{C}, 10 \mathrm{~s}$ at $55^{\circ} \mathrm{C}$ and $10 \mathrm{~s}$ at $72^{\circ} \mathrm{C}$ and a final hold of $1 \mathrm{~min}$ at $40^{\circ} \mathrm{C}$. Relative amounts of each viral transcript are expressed as the fold change in $\log _{2}$ of NP, F, HE, or M in infected cells treated with bacteria carrying antivirals compared to infected cells without antiviral treatment. To estimate the mRNA expression levels of $\mathrm{Mx}$ reactions were carried out under the same conditions previously mentioned. All reactions were performed in triplicate. All data were normalized to $\beta$-actin expression.

\section{Western Blot Analysis}

Sodium dodecyl sulfate-polyacrylamide gel electrophoresis (SDSPAGE) was performed using $15 \mu \mathrm{g}$ of protein from each sample on a $4-12 \%$ NuPAGE Bis-Tris Gel (Bio-Rad, USA). The proteins were blotted onto polyvinylidene difluoride (PVDF) membranes, blocked with $5 \%$ dry milk and incubated at $4^{\circ} \mathrm{C}$ overnight with anti-HE antibody (clone 8D2/E9; GrupoBios, Bios-Chile) diluted 1:2000 or anti- $\beta$-actin antibody (clone AC74, Sigma-Aldrich) diluted 1:500, followed by a $1 \mathrm{~h}$ incubation with the secondary antibody [rabbit-anti-mouse horseradish peroxidase (HRP), Invitrogen, USA] at a dilution of 1:20000. The blots were developed using Novex ${ }^{\circledR}$ ECL HRP Chemiluminescent Substrate (Invitrogen, USA) and exposed to Carestream Kodak Biomax Light film (sigma Aldrich, USA). The films were 
scanned and used for expression analysis with ImageJ $1.43 \mu$ software.

\section{Viral Plaque Assay}

The viral titre of the supernatant from ASK culture infected with ISAV HPR35; ASK infected and treated with attenuated E. coli HT115 carrying plasmid L4440 or ASK infected and treated with attenuated E. coli HT115 carrying dsRNA against HE, was determined with a plaque assay (Castillo-Cerda et al., 2014). ASK cells were seeded into 12 -well plates and incubated for 3 days at $15^{\circ} \mathrm{C}$. Then, the culture medium was removed from the monolayer, and $500 \mu \mathrm{L}$ of supernatant containing virus, ten-fold serially diluted, from different conditions (ISAV HPR35, ISAV HPR35 infection + E. coli HT115 pL4440 or ISAV HPR35 infection $+E$. coli HT115 dsRNA HE) or $500 \mathrm{uL}$ of supernatant from uninfected ASK culture (ASK control) were added. After $4 \mathrm{~h}$ at $15^{\circ} \mathrm{C}$, the inoculum was removed, and $3 \mathrm{~mL}$ of semi-solid medium was added to each well. The plates were incubated for 10 days postinfection at $15^{\circ} \mathrm{C}$. At day 10 post-infection, the cells were fixed in $1 \mathrm{~mL}$ of formalin $(37 \%)$ for $1 \mathrm{~h}$ at $25^{\circ} \mathrm{C}$, and the semi-solid medium was removed. For visualization, $2 \mathrm{~mL}$ of crystal violet (1\%) was added for $1 \mathrm{~h}$ at $25^{\circ} \mathrm{C}$, and the excess crystal violet was removed. Finally, the number of lysis plaques formed in wells was counted for each antiviral treatment.

\section{Statistical Analysis}

All experiments were performed in triplicate. The data were analyzed using GraphPad v. 5.01. Real-time PCR data were analyzed using Rest 2009 software. Protein expression data were analyzed using an ANOVA with Bonferroni's multiple comparison posttest. Viral plaque assay data were analyzed using the Wilcoxon test.

\section{Results}

\section{dsRNA Design and Production}

Identification of Conserved Regions of Four Genes Involved in the Viral Cycle of ISAV (NP, F, HE, and M)

To appropriately design the dsRNA sequences, one 500 bp conserved region (Supplementary Table 1) was identified in the alignment of the Chilean ISAV isolates considered in this study (Table 1) for each of the four viral genes NP, F, HE, and M. The characteristics of these conserved sequences are described in Table 3. Note that the sequence identity $(*)$ was the percentage of nucleotide of sequences that had the same residue at the same position in the alignment.

\section{Detection and Quantitation of dsRNA Produced in $E$. coli HT115 (DE3)}

The production of each dsRNA was observed in a $1 \% \mathrm{w} / \mathrm{v}$ agarose gel as one band of approximately $500 \mathrm{bp}$. These bands were purified, and conventional PCR reactions of the internal regions of the conserved sequences were performed. The expected size was observed for each purified dsRNA, with bands of 205, 224, 182 , and 200 bp for NP, F, HE, and M, respectively, demonstrating successful expression (Supplementary Figure 1A). Furthermore, dsRNAs were visualized and quantified in a bioanalyzer
(Supplementary Figure 1B). The concentration of each band was used to calculate the number of dsRNA copies produced by each milligram of bacteria. Values of $2.44 \times 10^{13}, 6 \times 10^{13}, 2.41 \times 10^{13}$, and $7.87 \times 10^{13}$ copies of $\mathrm{dsRNA} / \mathrm{mg}$ bacteria were obtained for $\mathrm{NP}, \mathrm{F}, \mathrm{HE}$, and $\mathrm{M}$, respectively.

\section{Delivery of dsRNA into ASK Cells Co-Localization Assay of E. coli HT115 (DE3) Overexpressing GFP in ASK Cells}

E. coli HT115 (DE3) overexpressing GFP was used in an attempt to evaluate the endocytosis of these bacteria after treatment with formaldehyde. Green E. coli HT115 (DE3) were observed near ASK cell membranes at $24 \mathrm{~h}$ post-incubation with bacteria (Figure 1, upper left panel) but were not uptaken, as observed

TABLE 3 | Analysis of each conserved sequence of four genes of ISAV.

\begin{tabular}{lccc}
\hline $\begin{array}{l}\text { Genomic } \\
\text { segment }\end{array}$ & $\begin{array}{c}\text { Size of } \\
\text { genomic } \\
\text { segment (bp) }\end{array}$ & $\begin{array}{c}\text { Nucleotide position } \\
\text { of conserved } \\
\text { sequence (start-term) }\end{array}$ & $\begin{array}{c}\text { Sequence } \\
\text { identity \%* }\end{array}$ \\
\hline Nucleoprotein & 1800 & $1076-1575$ & 89.2 \\
Fusion & 1367 & $335-834$ & 99.5 \\
Hemagglutinin & 1182 & $1-500$ & 99.4 \\
Matrix & 861 & $95-594$ & 92.7 \\
\hline
\end{tabular}

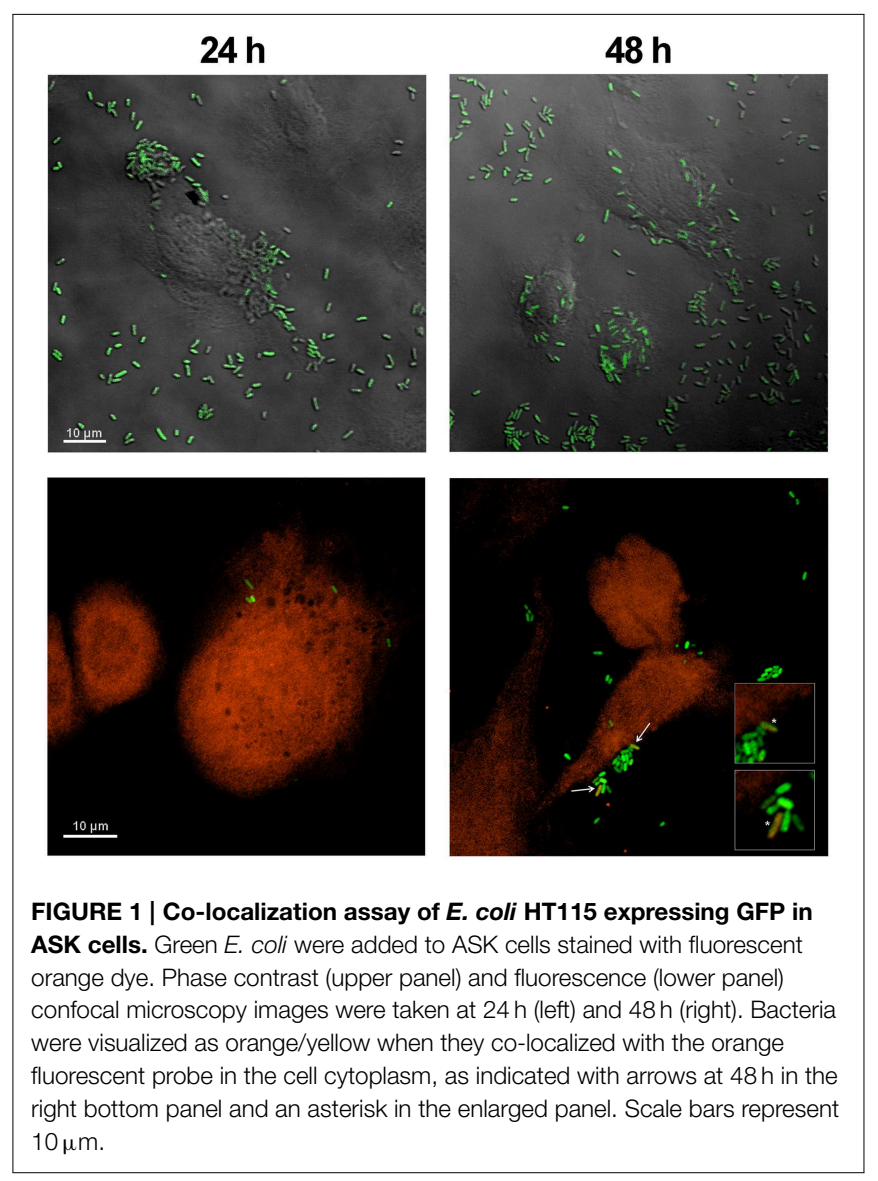


when a cytoplasmic probe was used in co-localization assays (Figure 1, bottom left panel). At $48 \mathrm{~h}$ post-incubation, a few bacteria (1 or $2 /$ cell) were present as an orange/yellow mark in conjunction with GFP fluorescence, indicating co-localization with ASK cytoplasm (Figure 1, arrows and asterisks in bottom right panel), suggesting the internalization uptake of bacteria. These data were confirmed using a Z-plane reconstruction (data not shown). This phenomenon was also observed at $96 \mathrm{~h}$ postincubation with bacteria, although no increase in the number of uptaken bacteria per cell was observed (data not shown).

\section{Effect of dsRNA \\ Effect of dsRNA Targeting NP, F, HE, or M on the Expression of Their Gene Targets}

To evaluate whether dsRNAs produced by E. coli HT115 were able to decrease the expression of viral genes, infected ASK cells were treated with bacteria expressing each dsRNA (NP, F, HE, or $\mathrm{M}$ ) independently, expressing all of the dsRNAs together in equal concentrations (NP/F/HE/M) or not expressing dsRNA. For purposes of comparison, the relative expression of viral genes in control (ISAV HPR35) and treated ASK cells (ISAV HPR35 + dsRNA) were measured. Relative amounts of each viral transcript are expressed as the fold change in NP, F, HE, or $\mathrm{M}$ in infected cells treated with bacteria carrying the antiviral, compared to infected cells without antiviral treatment. All data were normalized to $\beta$-actin expression. The expression levels of NP, F, and M mRNAs were not significantly affected by treatment with their specific dsRNAs (Figure 2A). However, mRNA expression of the gene encoding $\mathrm{HE}$ was significantly reduced (six-fold change in $\log _{2}$ ) by dsRNA against HE (Figures 2A,B).
HE mRNA expression was not affected when infected ASK cells were treated with empty vector (no dsRNA, pL4440) and decreased to a lesser degree (1-fold change in $\log _{2}$ ) when the cells were treated with a combination of equal parts of the bacteria carrying their corresponding dsRNAs (dsRNA NP/F/HE/M) (Figure 2B).

\section{Effect of dsRNA against HE on HE Protein Expression} HE protein expression was significantly decreased by $45 \%$ in infected ASK cells using dsRNA against HE (dsRNA HE) compared with infected and non-treated cells (ISAV HPR35) (Figure 3), by western blot analysis. On the other hand, HE protein expression in infected ASK cells treated with bacteria carrying equal amounts of dsRNA against NP, F, HE, and M (dsRNA NP/F/HE/M) or with empty bacteria (pL4440) was unaltered compared with the ISAV-infected control (ISAV HPR35).

\section{The Effect of HE dsRNA on the ISAV Viral Load in ASK Cultures}

To assess whether the decrease in the HE protein level correlated with a lower number of infectious viral particles, a viral plaque assay was performed. The viral titer $(\mathrm{PFU} / \mathrm{mL})$ in the supernatant of infected ASK cells treated with dsRNA against HE (dsRNA HE; $5.9 \times 10^{3} \mathrm{PFU} / \mathrm{mL}$ ) was 24 -fold lower than the viral titer in supernatants of non-treated cells (HPR35, $1.4 \times 10^{5} \mathrm{PFU} / \mathrm{mL}$ ). Bacteria carrying no dsRNA (pL4440) had no significant effect on ISAV viral titer (Figure 4). An uninfected cell control (ASK) was added to verify that cells did not form lysis plaques for other reasons (Figure 4).

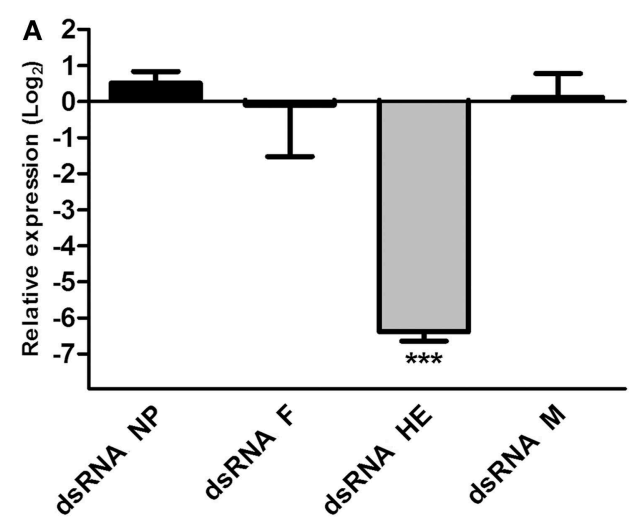

FIGURE 2 | Relative expression of viral mRNA in infected ASK cells treated with different dsRNAs. (A) Relative viral mRNA expression of NP, F, HE, and $M$ in ASK cells infected with ISAV HPR35 and treated with HT115 E. coli carrying dsRNA against NP (dsRNA NP), F (dsRNA F), HE (dsRNA HE), or M (dsRNA M). Data were compared with viral mRNA expression of infected but non-treated ASK cells and expressed as fold change in $\log _{2}$. (B) Relative expression of $\mathrm{HE}$ mRNA in ASK cells infected with ISAV HPR35 and treated with HT115 E. coli carrying dsRNA against HE (dsRNA HE), a mixture of the four

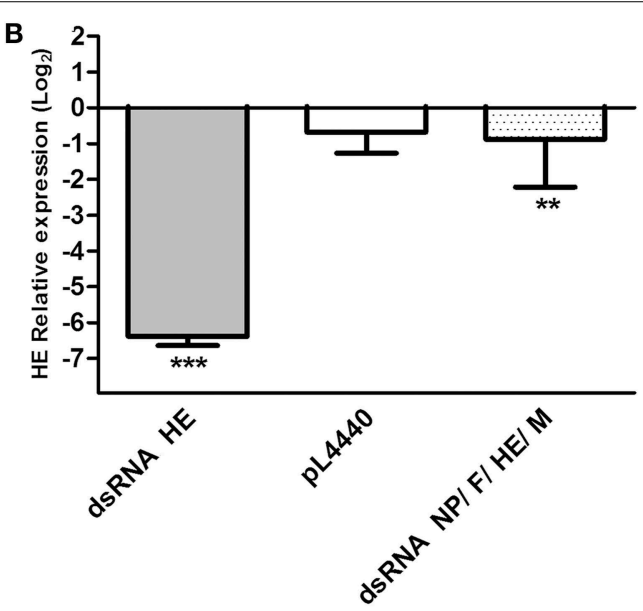

E. coli strains carrying each of the dsRNAs (dsRNA NP/F/HE/M) or E. coli carrying the empty vector (pL4440) compared with viral mRNA expression in infected but non-treated ASK cells. Data are expressed as fold change in $\log _{2}$. Bars represent the average results $(n=3)$, and the error bars represent standard errors of the means (SEM). $\left(^{* * *}\right)$ indicates significant differences between treated, infected ASK cells vs. untreated, infected ASK cells, $p<0.05$. **indicates significant differences between NP/F/HE/M-mix treated, infected ASK cells vs. HE treated, infected ASK cells, $p<0.05$. 


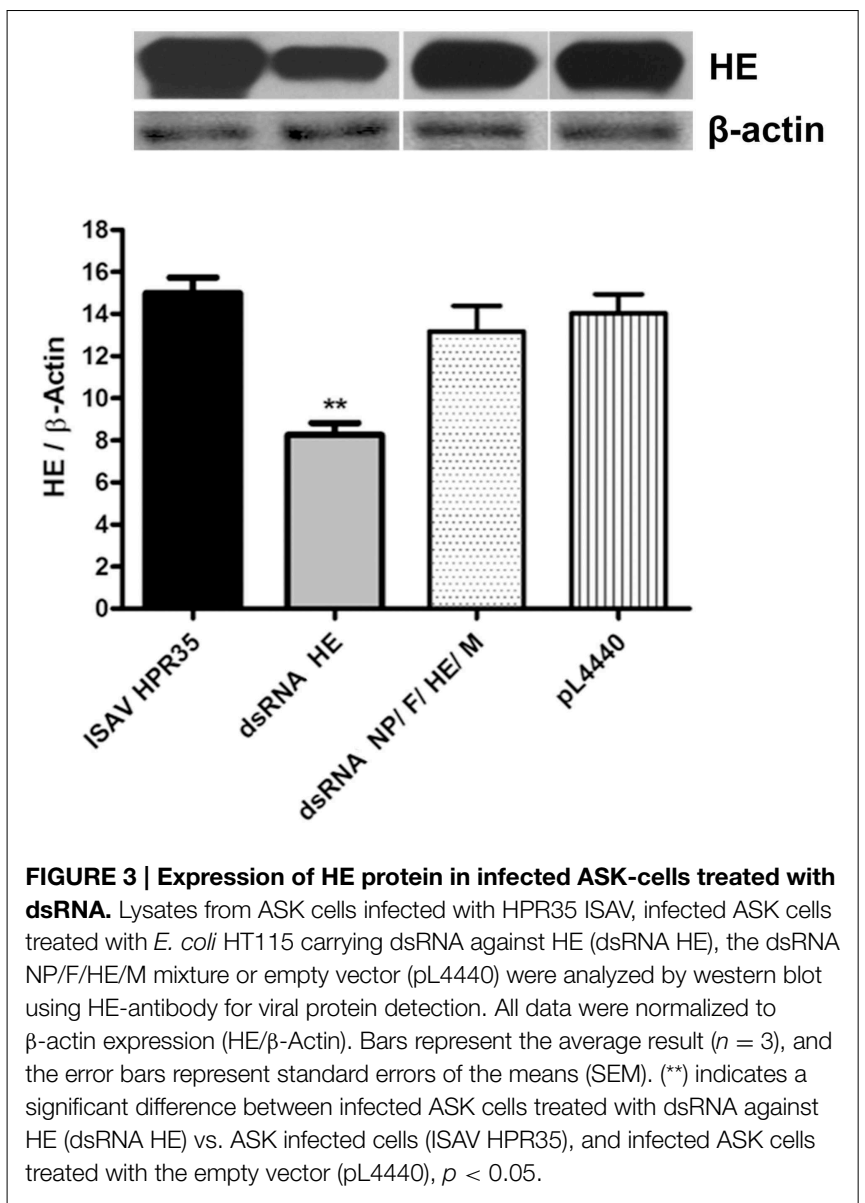

\section{The Effect of HE dsRNA on the CPE of ISAV in ASK Cultures}

Microscopic observations revealed characteristic phenotypic changes when ASK cells were infected with ISAV HPR35. At day 11 post-infection, infected cells showed an extensive CPE with numerous vacuolated and stellated-shaped cells with partial monolayer detachment (Figure 5B). In contrast, when infected cells were treated with HE dsRNA, the cells showed decreased CPE, no vacuolated cells and less monolayer detachment (Figure 5C). In infected cells treated with bacteria expressing no dsRNA against HE, the cellular damage observed was similar to that upon infection with ISAV with no additional treatment (Figure 5D). As a control, ASK cells after 11 days of cultivation are shown in Figure 5A.

\section{The Effect of dsRNAs on Mx Expression in ASK Cultures}

To evaluate the ability of dsRNAs produced by E. coli HT115 to induce expression of $\mathrm{Mx}$, a marker of the interferon pathway, uninfected ASK cells were treated with bacteria expressing each dsRNA (NP, F, HE, or M) independently or expressing no dsRNA (empty vector pL4440). All gene expression data were normalized to $\beta$-actin expression. The expression levels of $\mathrm{Mx}$ mRNAs were significantly

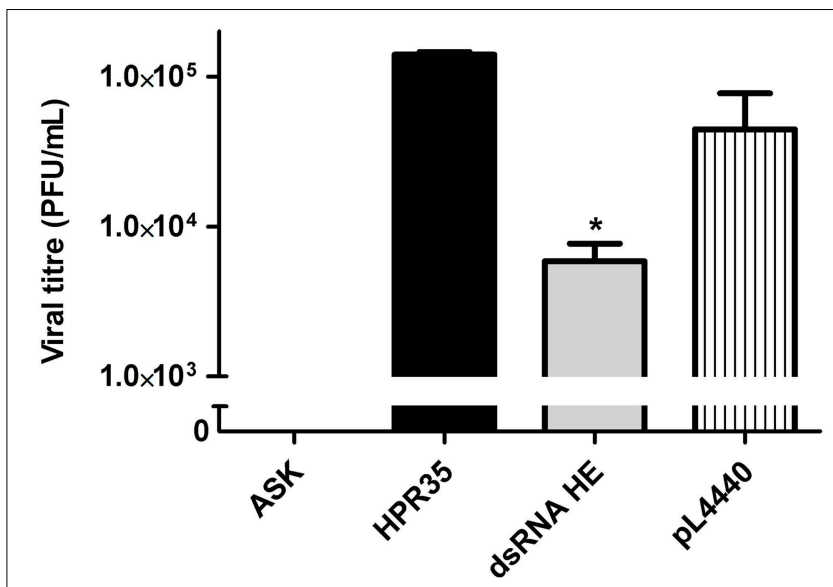

FIGURE 4 | Effect of HE dsRNA on viral titer (PFU/mL) in the supernatants of infected ASK cells. Viral titers (PFU/mL) of ISAV in the supernatants of ASK cells infected with ISAV HPR35 (HPR35), infected ASK cells treated with E. coli HT115 carrying dsRNA against HE (dsRNA HE) or empty vector ( $p L 4440)$. The supernatant of uninfected cells was added as an assay control (ASK). Bars represent the average result $(n=3)$, and the error bars represent standard errors of the means (SEM). $\left(^{*}\right)$ indicates a significant difference between HPR35-infected ASK cells treated with dsRNA against $\mathrm{HE}$ (dsRNA HE) vs. infected ASK cells (HPR35), $p<0.05$.
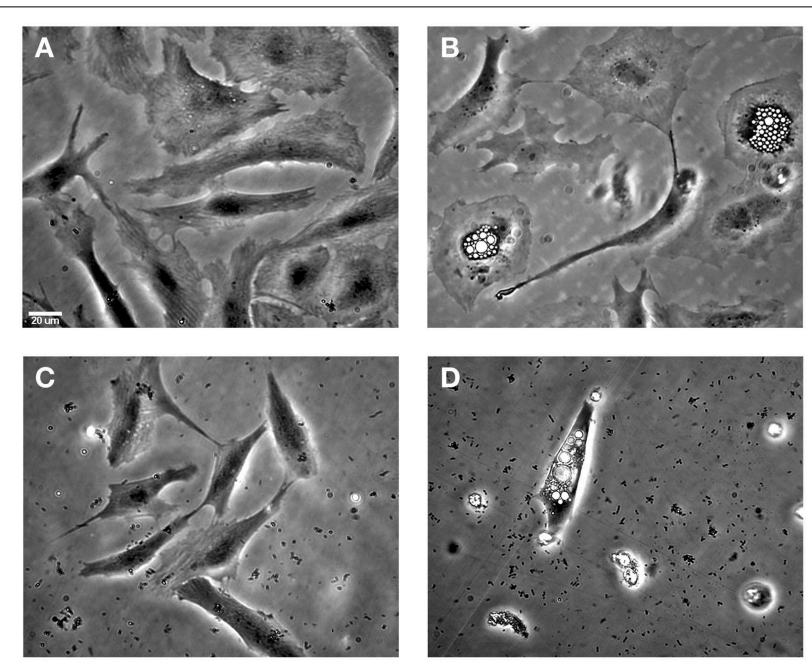

FIGURE 5 | The effect of HE dsRNA on induced CPEs in infected ASK cells. (A) Uninfected ASK cells at 11 days post-infection (B) ASK cells infected with HPR35 ISAV without treatment and (C) with the addition of $E$. coli carrying dsRNA against HE. (D) Infected ASK cells and treatment with E. coli HT1115 carrying empty vector pL4440 was included as a control. The CPEs observed in ASK cells infected as described were vacuolated cells and monolayer detachment. The scale bar represents $20 \mu \mathrm{m}$.

induced at similar extent by all dsRNAs (Supplementary Figure 2).

\section{Discussion}

RNAi is a promising methodology for developing new therapeutic and antiviral strategies (Gavrilov and Saltzman, 2012). RNAi 
has been suggested for the development of therapies aimed at the treatment of viral diseases and parasites in aquatic organisms (Lima et al., 2013), with successful reports on studies using RNAi against numerous viruses that cause problems in aquaculture. Sarathi et al. (2008b) were the first to show the antiviral ability of bacterially synthetized dsRNAs. They revealed that Vp28 dsRNA produced in bacteria was able to silence VP28 gene expression in WSSV. Similarly, others studies in vitro (Kim and Kim, 2011; Kim et al., 2012) have revealed that it is possible to control the virus causing viral hemorrhagic septicemia (VHSV), a single-stranded RNA genome virus that causes important viral diseases in a wide variety of wild and cultured fish species worldwide (Kim et al., 2012), using dsRNA antivirals in EPC (Epithelioma papulosum cyprinid) and CHSE214 (chinook salmon embryo) cells. Additionally, Kim and colleagues showed that long dsRNA antivirals are able to reduce the expression of the VHSV G gene, which encodes a glycoprotein, in a manner that is dependent on RNAi because they do not activate the interferon pathway (Kim et al., 2012). Later studies showed the feasibility of using RNAi ex vivo to inhibit the viral replication of cyprinid herpesvirus-3 (CyHV3 ) in cultured cells (Gotesman et al., 2014). Some of these successful studies support the methodology utilized in this study, which was based on the use of long bacterially synthesized dsRNAs, to inhibit replication of ISAV ex vivo by impairing the expression of viral proteins. To our knowledge, this is the first experimental approach using RNAi against the ISA virus. We searched conserved genomic regions within sequences of Chilean isolates that were available in the database (Table 1). Despite the few available sequences found for the NP and $M$ genes, one conserved genomic region of $500 \mathrm{bp}$ was detected in all genes of interest. Once we had designs for dsRNA, we used E. coli HT115 (DE3) for production and delivery of dsRNA because it is a good option for large-scale production and in vivo delivery in aquaculture systems (Sarathi et al., 2008a). These bacteria have been widely used for production and delivery of dsRNAs in other study models, such as C. elegans (Timmons and Fire, 1998; Kamath et al., 2001; Timmons et al., 2001). However, we observed that only one or two bacteria co-localized with the cytoplasm of ASK cells in our co-localization assay, suggesting that few bacteria were uptaken. We confirmed these observations performing PCR analysis of viral HE sequence using DNA preparations from ASK cells treated with attenuated bacteria (Supplementary Figure 3). These results agree with an observation by Simon and Leong (2002), who rarely observed gene transfer into CHSE-214 cells, another salmon-derived cell line, when using E. coli as a vector. Additionally, Grillot-Courvalin and colleagues observed that fewer than $0.1 \%$ of $\mathrm{CHO}$ cells (derived from Chinese hamster ovaries) received gene transfer when $E$. coli was used as a vector. However, when invasive E. coli were used, $6 \%$ of cells were found to be positive, indicating successful gene transfer (Grillot-Courvalin et al., 1998). Invasive E. coli have been found to act as a good gene delivery system in both phagocytic and non-phagocytic mammalian cells (Grillot-Courvalin et al., 1999), showing that using invasive non-pathogenic bacteria is a plausible strategy by which to obtain better uptake and delivery results. Despite the low number of uptaken bacteria in our experiments, the silencing efficiency of the four bacterially expressed dsRNAs against the NP,
F, HE, and $\mathrm{M}$ genes was investigated. The dsRNA against $\mathrm{HE}$ was found to significantly reduce mRNA expression. This result indicates that despite the low number of bacteria entering cells, the dsRNA input was sufficient to act in the ASK cells and specifically inhibit the expression of HE mRNA. It draws attention the fact of the mRNA expression of the gene encoding HE was significantly reduced (six-fold change in $\log _{2}$ ) by dsRNA against $\mathrm{HE}$, but it decreased to a lesser degree (1-fold change in $\log _{2}$ ) when the cells were treated with a combination of equal parts of the bacteria carrying their corresponding dsRNAs (dsRNA $\mathrm{NP} / \mathrm{F} / \mathrm{HE} / \mathrm{M})$. Similarly, HE protein expression was significantly decreased by $45 \%$ in infected ASK cells using dsRNA against HE (dsRNA HE) compared with infected and non-treated cells (ISAV HPR35) but HE protein expression in infected ASK cells treated with bacteria carrying equal amounts of dsRNA against $\mathrm{NP}, \mathrm{F}, \mathrm{HE}$, and M (dsRNA NP/F/HE/M) was unaltered compared with the ISAV-infected control. These findings strongly suggest a dose-dependency effect of dsRNA against HE in the assays. In addition, the absence of an effect on the HE mRNA level during the treatment with bacteria carrying empty L440 suggest that the inhibition of HE gene transcription was a response of the RNAi machinery induced by dsRNA against HE. However, this response seems to be combined with non-specific effects, since the expression of Mx gene (involved in the interferon pathway) is activated when non-infected ASK cells are treated with attenuated bacteria expressing dsRNA (data not shown). The fact that some dsRNA induces sequence specific antiviral activity in addition to non-specific immunity is not new, and it has been previously observed by other authors (LaFauce and Owens, 2009). dsRNA against HE was able to induce specific effect decreasing HE mRNA and consequently, decreasing HE protein expression. In contrast, dsRNA against NP, F, M had no effect decreasing the expression of their target viral proteins. This could be due to a limited uptake of bacteria by ASK cells. However, bacteria carrying the other dsRNA (against NP, F, and M) are also isogenic; among them the only difference is the insert, even insert size is $\sim 500 \mathrm{bp}$ in all cases. Furthermore, the number of dsRNA copies per mg of bacteria is very similar $\sim 10^{13}$ copies of dsRNA/mg bacteria in all cases. For this reason, we believe unlikely that differences in the antiviral effects were based on different bacterial uptake. The other reason may be explained by differences in the insert. It was reasonable that the target mRNAs for the other dsRNA molecules tested (NP, F, and M) were not silenced because other studies have shown that the degree of protection afforded by specific dsRNAs, varies between different targeted viral genes. The degree of protection conferred by dsRNA is wellknown to depend on the target viral gene (Robalino et al., 2005). In this work, we selected ISAV structural proteins as candidates for silencing. Some works have compared differences in silencing non-structural and structural protein genes and found no clear differences (Flores-Jasso et al., 2004; Sanjuktha et al., 2012). However, Sanjuktha and colleagues showed that the function of the encoded protein is a more important criterion for selection (Sanjuktha et al., 2012). Moreover, the gene silencing effect of dsRNA is likely to vary substantially with the targeted position on the mRNA (Luo and Chang, 2004). Robalino et al. (2005) reported that different mRNAs were differentially susceptible to 
sequence-dependent targeting. Until now, the reasons for the differences in RNAi efficacy have not been well-understood, but they may involve primary sequence and secondary structure properties of dsRNA and targeted viral mRNAs. Additionally, the binding of viral and/or cellular proteins to the targeted RNA sequence may prevent recognition by the RNA-induced silencing complex (Hasnoot et al., 2003).

The strong decrease in the HE mRNA level was reflected in a $45 \%$ decrease in protein expression, although the significant reduction in mRNA when all antivirals were used together, was not reflected in a significant protein reduction. These results likely occurred due to the high stabilization of the remaining mRNA, as has been shown in other viruses, such as equine infectious anemia virus (Martarano et al., 1994) and rabies virus (Palusa et al., 2012). Nonetheless, the decrease in the protein level in $45 \%$, was associated with a strong decrease in the viral titer, which decreased by 24 -fold. This effect was probably due to the combined response of RNAi pathway with non-specific effects induced in a sequence-independent manner, since the expression of Mx gene is activated in uninfected ASK cells treated with dsRNA against HE (Supplementary Figure 2). However, Mx expression was induced at similar extent by dsRNA HE and the other dsRNA molecules, which had no antiviral effect, hence, we suggest that the inhibition of HE gene transcription and the decrease in the viral titer occur mainly due to specific effects of dsRNA HE treatment. Concomitantly, the lower number of infective viral particles was reflected in a minor CPE in infected ASK cells, and cells with hallmark morphologic changes (vacuolated cells) and monolayer detachment associated with viral infection were not observed. These effects are not specific to ISAV because the same phenomenon has been observed when gene expression is silenced ex vivo using RNAi against other viruses. In the case of goatpox, a decline in the number of infective viral particles was reflected in a reduced CPE in Vero cells (Zhao et al., 2012). A similar result was observed when RNAi was used against the equine encephalitis virus in Vero cells and U87MG; all effective RNAi silencing of the target gene decreased the CPE associated with viral infection (Lundberg et al., 2013).

The results obtained in this work using an ex vivo model support for the first time the possible use of RNAi against the ISA virus. However, the administration of RNAi in vivo is still a substantial challenge. Some reports have already studied the

\section{References}

Abid, A., Davied, S. J., Waines, P., Emery, M., Castex, M., Gioacchini, G., et al. (2013). Dietary synbiotic application modulates Atlantic salmon (Salmo salar) intestinal microbial communities and intestinal immunity. Fish Shellfish Immunol. 35, 1948-1956. doi: 10.1016/j.fsi.2013.09.039

Altschul, S. F., Gish, W., Miller, W., Myers, E. W., and Lipman, D. J. (1990). Basic local alignment search tool. J. Mol. Biol. 215, 403-410.

Castillo-Cerda, M. T., Cottet, L., Toro-Ascuy, D., Spencer, E., and Cortez-San Martín, M. (2014). Development of plaque assay for Chilean Infectious salmon anaemia Virus, application for virus purification and titration in salmon ASK cells. J. Fish Dis. 37, 989-995. doi: 10.1111/jfd.12198

Cottet, L., Cortez-San Martin, M., Tello, M., Olivares, E., Rivas-Aravena, A., Vallejos, E., et al. (2010). Bioinformatics analysis of the genome of infectious salmon efficacy of RNAi administered in vivo (LaFauce and Owens, 2009). These studies have shown that RNAi confers protective effects by slightly reducing the viral titer of Penaeus merguiensis densovirus, and it has a large effect on the prevention of mortality in treated crickets (LaFauce and Owens, 2009). This fact indicates that protective non-specific effects likely occur in some instances of RNAi, as we also observed with dsRNA against HE.

\section{Conclusion}

In light of the results presented, we demonstrated that long dsRNA against HE elicits the RNAi process in salmon cells, and these dsRNA molecules are able to reduce ISAV replication and viral load in infected ASK cells. Although it seems that dsRNA also induces non-specific effects of the immune response. This strategy could still be improved and optimized, leading us to design new methodologies in the future using in vivo models to provide an efficient tool for ISAV control in cultured fish.

\section{Author Contributions}

KG drafted the manuscript. KG, SRA, and AD made cell cultures, real time PCR, WB, and ECP assays and they analyze the results. SRA and SRC made co-localization assays of bacteria in culture cell. SRC and GH made viral plaque assays. SRA also made statistical analysis. RE participated analysis of results. JR conceived the study and participated in its design and coordination. All authors read and approved the final manuscript.

\section{Acknowledgments}

Research reported in this was supported by FONDEF D10I1056 and FONDECYT Postdoctorado 3120081 is gratefully acknowledged. We also thank Paulina Rubilar for her invaluable guidance.

\section{Supplementary Material}

The Supplementary Material for this article can be found online at: http://www.frontiersin.org/journal/10.3389/fmicb. 2015.00300/abstract anemia virus associated with outbreaks with high mortality in Chile. J. Virol. 84, 11916-11928. doi: 10.1128/JVI.01202-10

Cottet, L., Rivas-Aravena, A., Cortez-San Martin, M., Sandino, A., and Spencer, E. (2011). Infectious salmon anemia virus-genetics and pathogenesis. Virus Res. 155, 10-19. doi: 10.1016/j.virusres.2010.10.02

Dannevig, B. H., Falk, K., and Namork, E. (1995). Isolation of the causal virus of infectious salmon anaemia (ISA) in a long-term cell line from Atlantic salmon head kidney. J. Gen. Virol. 76, 1353-1359. doi: 10.1099/0022-1317-76-6-1353

DeVincenzo, J., Lambkin-Williams, R., Wilkinson, T., Cehelsky, J., Nochur, S., Walsh, E., et al. (2010). A randomized, double-blind, placebo-controlled study of an RNAi-based therapy directed against respiratory syncytial virus. Proc. Natl. Acad. Sci. U.S.A. 107, 8800-8805. doi: 10.1073/pnas.0912186107

Devold, M., Krossay, B., Aspehaug, V., and Hylund, A. (2000). Use of RT-PCR for diagnosis of infectious salmon anaemia virus (ISAV) in carrier sea trout 
Salmo trutta after experimental infection. Dis. Aquat. Org. 40, 9-18. doi: 10.3354/dao040009

Di Génova, A., Aravena, A., Zapata, L., González, M., Maass, A., and Iturra, P. (2011). SalmonDB: a bioinformatics resource for Salmo salar and Oncorhynchus mykiss. Database 2011:bar050. doi: 10.1093/database/bar050

Evensen, O., Thorud, K. E., and Olsen, Y. A. (1991). A morphological study of the gross and light microscopic lesions of infectious anaemia in Atlantic salmon (Salmo salar). Res. Vet. Sci. 51, 215-222. doi: 10.1016/0034-5288(91)90017-I

Falk, K., Aspehaug, V., Vlasak, R., and Endresen, C. (2004). Identification and characterization of viral structural proteins of infectious salmon anemia virus. J. Virol. 78, 3063-3071. doi: 10.1128/JVI.78.6.3063-3071.2004

Flores-Jasso, C., Valdes, V., Sampieri, A., Valadez-Graham, V., Recillas-Targa, F., and Vaca, L. (2004). Silencing structural and nonstructural genes in baculovirus by RNA interference. Virus Res. 102, 75-84. doi: 10.1016/j.virusres.2004.01.018

García, K., Díaz, A., Navarrete, A., Higuera, G., Guiñez, E., and Romero, J. (2013). "New strategies for control, prevention and treatment of ISA virus in aquaculture," in The Microbial Pathogens and Strategies for Combating Them: Science, Technology and Education, ed A. Méndez-Vilas (Badajoz: Formatex Research Center), 587-597.

Gavrilov, K., and Saltzman, W. M. (2012). Therapeutic siRNA: principles, challenges, and strategies. Yale J. Biol. Med. 85, 187-200.

Gotesman, M., Soliman, H., Besch, R., and El-Matbouli, M. (2014). In vitro inhibition of Cyprinid herpesvirus-3 replication by RNAi. J. Virol. Methods 206, 63-66. doi: 10.1016/j.jviromet.2014.05.022

Gregory, R. I., Chendrimada, T. P., Cooch, N., and Shiekhattar, R. (2005). Human RISC couples microRNA biogenesis and posttranscriptional gene silencing. Cell 123, 631-640. doi: 10.1016/j.cell.2005.10.022

Grillot-Courvalin, C., Goussard, S., and Courvalin, P. (1999). Bacteria as gene delivery vectors for mammalian cells. Curr. Opin. Biotech. 10:477-481. doi: 10.1016/S0958-1669(99)00013-0

Grillot-Courvalin, C., Goussard, S., Huetz, F., Ojcius, D., and Courvalin, P. (1998). Functional gene transfer from intracellular bacteria to mammalian cells. Nat. Biotech. 16, 862-866. doi: 10.1038/nbt0998-862

Hammond, S. M. (2005). Dicing and slicing: the core machinery of the RNA interference pathway. FEBS Lett. 579, 5822-5829. doi: 10.1016/j.febslet.2005. 08.079

Hammond, S. M., Bernstein, E., Beach, D., and Hannon, G. J. (2000). An RNAdirected nuclease mediates posttranscriptional gene silencing in Drosophila cells. Nature 404, 293-296. doi: 10.1038/35005107

Hannon, G., and Conklin, D. (2004). RNA interference by short hairpin RNAs expressed in vertebrate cells. Methods Mol. Biol. 257, 255-266. doi: 10.1385/159259-750-5:255

Hasnoot, P. C., Cupac, D., and Berkhout, B. (2003). Inhibition of virus replication by RNA interference. J. Biomed. Sci. 10(6 Pt 1), 607-616. doi: 10.1007/BF02256311

Kamath, R., Martinez-Campos, M., Zipperlen, P., Fraser, A., and Ahringer, J. (2001). Effectiveness of specific RNA-mediated interference through ingested double-stranded RNA in Caenorhabditis elegans. Genome Biol. 2, research0002.1-research0002.10. doi: 10.1186/gb-2000-2-1-research0002

Kim, M. S., Jee, B. Y., Cho, M. Y., Kim, J. W., Jeong, H. D., and Kim, K. H. (2012). Fugu double U6 promoter-driven long double-stranded RNA inhibits proliferation of viral hemorrhagic septicemia virus (VHSV) in fish cell lines. Arch. Virol. 157, 1029-1038. doi: 10.1007/s00705-012-1275-1

Kim, M. S., and Kim, K. H. (2011). Inhibition of viral hemorrhagic septicemia virus replication using a short hairpin RNA targeting the G gene. Arch. Virol. 156, 457-464. doi: 10.1007/s00705-010-0882-y

Krossøy, B., Hordvik, I., Nilsen, F., Nylund, A., and Endresen, C. (1999). The putative polymerase sequence of infectious salmon anemia virus suggests a new genus within the Orthomyxoviridae. J. Virol. 73, 2136-2142.

Kulshreshtha, V., Kibenge, M., Salonius, K., Simard, N., Riveroll, A., and Kibenge, F. (2010). Identification of the $3^{\prime}$ and $5^{\prime}$ terminal sequences of the 8 rna genome segments of European and North American genotypes of infectious salmon anemia virus (an orthomyxovirus) and evidence for quasispecies based on the non-coding sequences of transcripts. Virol. J. 7, 338. doi: 10.1186/1743-422X7-338

LaFauce, K., and Owens, L. (2009). RNA interference reduces PmergDNV expression and replication in an in vivo cricket model. J. Invertebr. Pathol. 100, 111-115. doi: 10.1016/j.jip.2008.10.006
La Fauce, K., and Owens, L. (2012). Dietary uptake of green fluorescent protein for delivery of dsRNA to induce RNA interference. J. Mar. Sci. Res. Dev. 2, 4. doi: 10.4172/2155-9910.1000114

Larkin, M. A., Blackshields, G., Brown, N. P., Chenna, R., McGettigan, P. A., McWilliam, H., et al. (2007). Clustal W and Clustal X version 2.0. Bioinformatics 23, 2947-2948. doi: 10.1093/bioinformatics/btm404

Lima, P. C., Harris, J. O., and Cook, M. (2013). Exploring RNAi as a therapeutic strategy for controlling disease in aquaculture. Fish Shellfish Immunol. 34, 729-743. doi: 10.1016/j.fsi.2012.11.037

Lundberg, L., Pinkham, C., Baer, A., Amaya, M., Narayanan, A., Wagstaff, K., et al. (2013). Nuclear import and export inhibitors alter capsid protein distribution in mammalian cells and reduce Venezuelan Equine Encephalitis Virus replication. Antivir. Res. 100, 662-672. doi: 10.1016/j.antiviral.2013.10.004

Luo, K., and Chang, D. (2004). The gene-silencing efficiency of siRNA is strongly dependent on the local structure of mRNA at the targeted region. Biochem. Biophys. Res. Commun. 318, 303-310. doi: 10.1016/j.bbrc.2004. 04.027

Martarano, L., Stephens, R., Rice, N., and Derse, D. (1994). Equine infectious anemia virus trans-regulatory protein Rev controls viral mRNA stability, accumulation, and alternative splicing. J. Virol. 68, 3102-3111.

Mjaaland, S., Rimstad, E., and Cunningham, C. O. (2002). "Molecular diagnosis of infectious salmon anaemia," in Molecular Diagnosis of Salmonid Diseases, ed C. O. Cunningham (Dordrecht: Kluwer Academic Publishers), 1-22. doi: 10.1007/978-94-017-2315-2_1

Müller, A., Markussen, T., Drabløs, F., Gjøen, T., Jørgensen, T. Ø., Solem, S. T., et al. (2010). Structural and functional analysis of the hemagglutininesterase of infectious salmon anaemia virus. Virus Res. 151, 131-141. doi: 10.1016/j.virusres.2010.03.020

Olsvik, P., Lie, K., Jordal, A., Nilsen, T., and Hordvik, I. (2005). Evaluation of potential reference genes in real-time RT-PCR studies of Atlantic salmon. BMC Mol. Biol. 6:21. doi: 10.1186/1471-2199-6-21

Palese, P., and Shaw, M. L. (2007). "Orthomyxoviridae: the viruses and their replication," in The Fields Virology, 5th Edn., eds D. M. Knipe and P. M. Howley (Philadelphia, PA: Lippincott Williams \& Wilkins), 1647-1689.

Palusa, S., Ndaluka, C., Bowen, R., Wilusz, C., and Wilusz, J. (2012). The $3^{\prime}$ Untranslated Region of the Rabies Virus Glycoprotein mRNA Specifically Interacts with Cellular PCBP2 Protein and Promotes Transcript Stability. PLoS ONE 7:e33561. doi: 10.1371/journal.pone.0033561

Peng, J., Zhao, Y., Mai, J., Pang, W. K., Wei, X., Zhang, P., et al. (2005). Inhibition of hepatitis B virus replication by various RNAi constructs and their pharmacodynamic properties. J. Gen. Virol. 86, 3227-3234. doi: 10.1099/vir.0. 81171-0

Posiri, P., Ongvarrasopone, C., and Panyim, S. (2013). A simple one-step method for producing dsRNA from E. coli to inhibit shrimp virus replication. J. Virol. Methods 188, 64-69. doi: 10.1016/j.jviromet.2012.11.033

Provost, P., Dishart, D., Doucet, J., Frendewey, D., Samuelsson, B., and Radmark, O. (2002). Ribonuclease activity and RNA binding of recombinant human Dicer. EMBO. J. 21, 5864-5874. doi: 10.1093/emboj/cdf578

Raynard, R. S., Murray, A. G., and Gregory, A. (2001). Infectious salmon anaemia virus in wild fish from Scotland. Dis. Aquat. Organ. 46, 93-100. doi: 10.3354/dao046093

Robalino, J., Bartlett, T., Shepard, E., Prior, S., Jaramillo, G., Scura, E., et al. (2005). Double stranded RNA induces sequence specific antiviral in addition to nonspecific immunity in marine shrimp: convergence of RNA interference and innate immunity in the invertebrate antiviral response? J. Virol. 79, 13561-13571. doi: 10.1128/JVI.79.21.13561-13571.2005

Ruiz, S., Schyth, B. D., Encinas, P., Tafalla, C., Estepa, A., Lorenzen, N., et al. (2009). New tools to study RNA interference to fish viruses: fish cell lines permanently expressing siRNAs targeting the viral polymerase of viral hemorrhagic septicemia virus. Antiviral Res. 82, 148-156. doi: 10.1016/j.antiviral.2009.02.200

Sanjuktha, M., Stalin, R. V., Aravindan, K., Alavandi, S. V., Poornima, M., and Santiago, T. C. (2012). Comparative efficacy of double-stranded RNAs targeting WSSV structural and nonstructural genes in controlling viral multiplication in Penaeus monodon. Arch. Virol. 157, 993-998. doi: 10.1007/s00705-012-1258-2

Sarathi, M., Simon, M. C., Ahmed, V. P., Kumar, S. R., and Hameed, A. S. (2008b). Silencing VP28 gene of white spot syndrome virus of shrimp by bacterially expressed dsRNA. Mar. Biotech. (NY). 10, 198-206. doi: 10.1007/s10126-0079052-y 
Sarathi, M., Simon, M. C., Venkatesan, C., and Hameed, A. S. (2008a). Oral administration of bacterially expressed VP28dsRNA to protect Penaeus monodon from white spot syndrome virus. Mar. Biotech. (NY) 10, 242-249. doi: 10.1007/s10126-007-9057-6

Simon, M., and Leong, J. A. (2002). Gene transfer to fish cells by attenuated invasive Escherichia coli. Mar. Biotech. (NY) 4, 303-309. doi: 10.1007/s10126-002-0022-0

Tijsterman, M., and Plasterk, R. (2004). Dicers at RISC; the mechanism of RNAi. Cell 117, 1-3. doi: 10.1016/S0092-8674(04)00293-4

Timmons, L., Court, D., and Fire, A. (2001). Ingestion of bacterially expressed dsRNAs can produce specific and potent genetic interference in Caenorhabditis elegans. Gene 263, 103-112. doi: 10.1016/S0378-1119(00)00579-5

Timmons, L., and Fire, A. (1998). Specific interference by ingested dsRNA. Nature 395, 854. doi: 10.1038/27579

Zhao, Z., Wu, G., Zhu, X., Yan, X., Dou, Y., Li, J., et al. (2012). RNA interference targeting virion core protein ORF095 inhibits Goatpox virus replication in Vero cells. Virol. J. 9, 48. doi: 10.1186/1743422X-9-48

Conflict of Interest Statement: Jaime Romero, Katherine García, and Álvaro Díaz hold a patent, number 1473-2014. Requested patent 2014-01473 PCT Chile. The authors declare that the research was conducted in the absence of any commercial or financial relationships that could be construed as a potential conflict of interest.

Copyright (c) 2015 García, Ramírez-Araya, Díaz, Reyes-Cerpa, Espejo, Higuera and Romero. This is an open-access article distributed under the terms of the Creative Commons Attribution License (CC BY). The use, distribution or reproduction in other forums is permitted, provided the original author(s) or licensor are credited and that the original publication in this journal is cited, in accordance with accepted academic practice. No use, distribution or reproduction is permitted which does not comply with these terms. 